PENENTUAN NASABAH PENERIMA REWARD PRODUK GOLD DENGAN METODE SIMPLE ADDITIVE WEIGHTING (SAW) STUDI KASUS : PT. PINJAM INDONESIA

Riki Ruli A. Siregar; Faizal Fachrurrozi

IMPLEMENTASI METODE BACKWARD CHAINING PADA DATA WAREHOUSE DAOP 1 JAKARTA PT. KAI (PERSERO) Rakhmat Arianto; Chandra Bagus Sugiarto

IMPLEMENTASI METODE DETEKSI TEPI CANNY PADA OBJEK SEBAGAI MODEL KEAMANAN APLIKASI PADA SMARTPHONE ANDROID

Abdul Haris; Andi Prasetyo

ANALISA DATA DAN PERANCANGAN APLIKASI SERVICE PELANGGAN PT. JNE UNTUK PENINGKATAN KUALITAS LAYANAN

Dewi Arianti Wulandari; Sonny Syahrindra Putra

JARINGAN AD-HOC VEHICULAR (VANET) : TINJAUAN TENTANG ARSITEKTUR, KARAKTERISTIK, APLIKASI, DAN PROTOKOL MEDIUMACCESS CONTROL (MAC)

Rosida Nur Aziza

PERANCANGAN APLIKASI PENJADWALAN MATA KULIAH MENGGUNAKAN METODE CONSTRAINT PROGRAMMING Syam Gunawan

RANCANGAN TATA KELOLA PEREMAJAAN RUANG KELAS DIREKTORAT PEMBINAAN SEKOLAH DASAR

Ratna Mutu Manikam; Purwanto

PENGEMBANGAN AMORIK MENGGUNAKAN METODE GARIS SINGGUNG TERHADAP DUA LINGKARAN DAN PERSAMAAN KURVA BEZIER ORDE DUA.

Darma Rusjidi

OPTIMALISASI PENGAMBILAN KEPUTUSAN PENILAIAN KINERJA DOSEN PADA PERGURUAN TINGGI ISLAM XYZ MENGGUNAKAN AHP (ANALYTICAL HIERARCHY PROCESS)

Rahma Farah Ningrum

PENGAMANAN SMS PADA TELEPON SELULER BERBASIS ANDROID MENGGUNAKAN ALGORITMA TRIPLE DES Raka Yusuf; $M$. Rival Suheri

APLIKASI LATIHAN SOAL UJIAN TEORI SURAT IZIN MENGEMUDI BERBASIS WEB Harni Kusniyati; Raka Yusuf; Andri Setiawan

RANCANG BANGUN SIMULASI TERJADINYA LISTRIK DENGAN SUMBER DAYA SAMPAH BERBASIS MULTIMEDIA (STUDI KASUS : TPST BANTAR GEBANG)

Yasni Djamain; Ika Fitriyani Putri

\begin{tabular}{|c|c|c|c|c|c|c|}
\hline \multirow{2}{*}{ 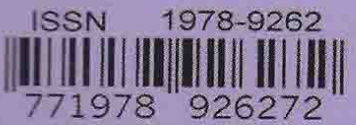 } & \multicolumn{6}{|c|}{ SEKOLAH TINGGI TEKNIK - PLN (STT-PLN) } \\
\hline & PETIR & VOL. 9 & NO. 1 & HAL. 1 - 87 & JAKARTA, MARET 2016 & ISSN $1978-9262$ \\
\hline
\end{tabular}




\title{
PERANCANGAN APLIKASI PENJADWALAN MATA KULIAH MENGGUNAKAN METODE CONSTRAINT PROGRAMMING
}

\author{
Syam Gunawan \\ Program Studi Sistem Informasi, STMIK-INDONESIA, Jakarta \\ syam.gun@gmail.com
}

\begin{abstract}
ABSTRAK
Perguruan tinggi adalah satuan pendidikan penyelenggara pendidikan tinggi. Ujung tombak kegiatan pembelajaran di Perguruan Tinggi berada di Program Studi. Program studi harus mampu mengatur diri sendiri serta memberikan pelayanan prima. Dalam upaya meningkatkan efisiensi, efektivitas, transparansi dan akuntabilitas penyelenggaraan program studi maka perlu adanya Sistem Informasi Akademik. Salah satu komponen penting dalam kegiatan pembelajaran adalah Jadwal Perkuliahan. Jadwal Perkuliahan adalah daftar yang memuat atau berisi nama mata kuliah, dosen mata kuliah, waktu, ruang perkuliahan dan lain sebagainya. Jadwal Perkuliahan harus sudah tersedia sebelum kegiatan pelaksanaan perkuliahan dilaksanakan. Membangun Jadwal Perkuliahan untuk suatu program studi yang besar memang merupakan suatu pekerjaan yang kompleks, sehingga dalam pelaksanaannya sering terjadi tabrakan jam, ruang, dosen mempunyai jadwal yang sama untuk mata kuliah yang berbeda, mahasiswa mengikuti perkuliahan pada waktu yang sama pada mata kuliah yang berbeda dan lain sebagainya. Hal ini jika dilihat sepintas merupakan masalah yang ringan, namun jika dibiarkan akan sangat berpengaruh pada kegiatan akademik secara keseluruhan. Oleh karena itu, Jadwal Perkuliahan sebaiknya dimasukkan sebagai bagian dari program Sistem Informasi Akademik.
\end{abstract}

Kata Kunci: jadwal kuliah, Constraint Programming, Sistem Informasi Akademik.

\section{PENDAHULUAN}

Kegiatan perkuliahan umumnya dilakukan melalui tatap muka antara pengajar (dosen) dengan mahasiswa dalam waktu tertentu yang disusun dalam jadwal mata kuliah. Penjadwalan mata kuliah ini dilakukan setiap pergantian semester dan membutuhkan waktu, tenaga serta ketelitian untuk membuatnya.

Dalam pembuatan jadwal mata kuliah harus memenuhi aturan-aturan penjadwalan untuk menghindari terjadinya masalah seperti adanya jadwal dosen yang mengajar mata kuliah yang berbeda dalam waktu bersamaan atau tidak tersedianya ruangan untuk mata kuliah tertentu.

Untuk mengatasi permasalahan di atas, dibutuhkan suatu sistem pendukung perkuliahan untuk membuat jadwal secara otomatis sehingga dapat meningkatkan efisiensi kerja dari berbagai pihak. Aplikasi ini juga diharapkan dapat membantu mahasiswa yang ingin mengambil mata kuliah lebih dari jumlah SKS paket yang ditawarkan, agar tidak mengalami kesulitan untuk pemilihan mata kuliah yang ingin ditempuh pada semester tersebut.

Dalam Tugas Akhir ini dirancang sebuah aplikasi untuk mengatur jadwal kuliah secara otomatis agar menghasilkan keluaran berupa jadwal kuliah yang optimal, namun jadwal ini masih memungkinkan untuk diubah sesuai dengan keinginan dari user.

\section{Tinjauan Sistem Berjalan}

Sistem informasi akademik STMIK Indonesia selama ini sudah menggunakan sistem yang telah terkomputerisasi dan proses pengolahan jadwal mata kuliah pun sudah dilakukan dengan menggunakan program yang telah terintegrasi dengan menggunakan database, namun hanya bisa diakses di dalam kampus saja atau belum dapat diakses secara online. Keadaan demikian mengakibatkan antrian mahasiswa yang akan mengakses jadwal kuliah karena keterbatasan teknologi yang tersedia. Sistem akademik yang telah berjalan memiliki beberapa kelemahan diantaranya pengisian jadwal kuliah bersifat manual yaitu mahasiswa datang ke kampus untuk melihat jadwal program studi dan pelayanan sistem akademik di STMIK Indonesia yang tidak efisien. Salah satunya pada penyampaian informasi jadwal mata kuliah hanya ditampilkan dalam bentuk kertas yang dapat diambil melalui BAAK dan disampaikan melalui papan pengumuman yang dapat menghabiskan waktu dan biaya. 


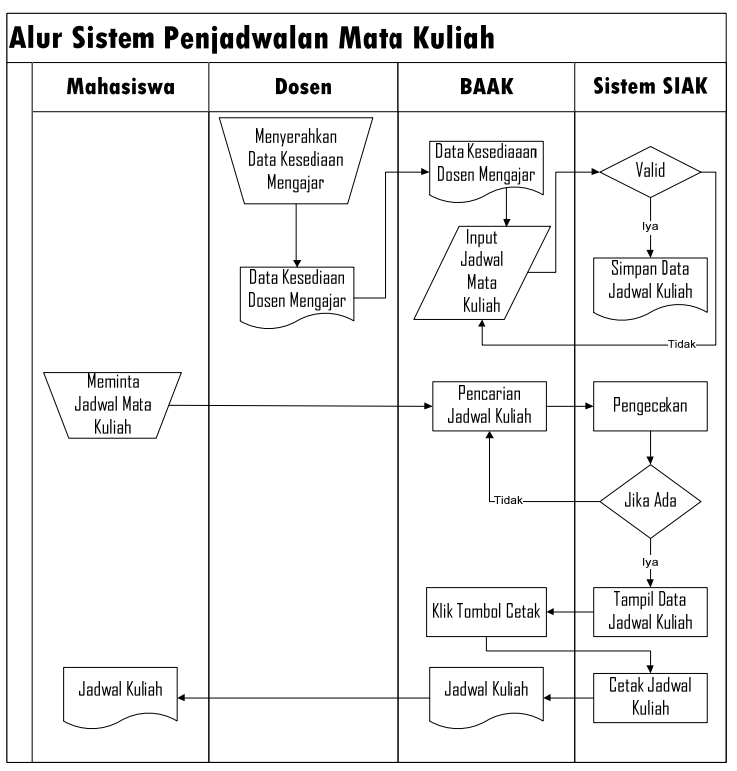

Gambar 1. Flow map Penjadwalan Matakuliah

\section{Analisa Masalah}

Untuk menyelesaikan suatu masalah, kita harus dapat mengidentifikasi penyebab timbulnya masalah, baru bisa menganalisis sebuah sistem, analisis yang digunakan yaitu analisis pieces. Analisis ini digunakan untuk menganalisa system.

Tabel 3.1. Cause and effect analysis

\begin{tabular}{|c|c|c|c|}
\hline \multicolumn{2}{|c|}{ Analisa Sebab dan Akibat } & \multicolumn{2}{|c|}{$\begin{array}{l}\text { Tujuan-Tujuan Perbaikan } \\
\text { Sistem }\end{array}$} \\
\hline $\begin{array}{l}\text { Masalah/pelu } \\
\text { ang }\end{array}$ & $\begin{array}{l}\text { Cause-Effect } \\
\text { Analysis }\end{array}$ & $\begin{array}{l}\text { Tujuan } \\
\text { Sistem }\end{array}$ & $\begin{array}{l}\text { Batasan } \\
\text { Sistem }\end{array}$ \\
\hline $\begin{array}{l}\text { - Model } \\
\text { Pelayanan } \\
\text { dalam } \\
\text { penyampaian } \\
\text { jadwal kuliah } \\
\text { terkesan tidak } \\
\text { efisien. }\end{array}$ & $\begin{array}{l}\text { Cause : } \\
\text { Sistem yang } \\
\text { sedang } \\
\text { berjalan } \\
\text { hanya bisa } \\
\text { diakses di } \\
\text { dalam } \\
\text { lingkungan } \\
\text { kampus saja } \\
\text { atau belum } \\
\text { online. } \\
\text { Effect : } \\
\text { Informasi } \\
\text { yang disajikan } \\
\text { tidak up to } \\
\text { date dan } \\
\text { sering } \\
\text { mengalami } \\
\text { keterlambatan }\end{array}$ & $\begin{array}{l}\text { Untuk } \\
\text { memudahka } \\
\mathrm{n} \text { dalam } \\
\text { mahasiswa } \\
\text { melihat } \\
\text { jadwal mata } \\
\text { kuliah. }\end{array}$ & $\begin{array}{l}\text { Dari segi } \\
\text { service yaitu } \\
\text { layanan yang } \\
\text { diberikan. }\end{array}$ \\
\hline $\begin{array}{l}\text { Informasi } \\
\text { yang } \\
\text { disajikan } \\
\text { tidak up to } \\
\text { date. }\end{array}$ & $\begin{array}{l}\text { Cause : } \\
\text { Informasi tidak } \\
\text { di update dan } \\
\text { tidak ada } \\
\text { mengontrolan } \\
\text { secara } \\
\text { berkala. } \\
\text { Effect : } \\
\text { Apabila suatu } \\
\text { saat terjadi } \\
\text { kesalahan, } \\
\text { sangatlah sulit } \\
\text { untuk } \\
\text { dideteksi. }\end{array}$ & $\begin{array}{l}\text { Dapat } \\
\text { mengefisien } \\
\text { si waktu } \\
\text { bagi } \\
\text { mahasiswa } \\
\text { dan dosen } \\
\text { untuk } \\
\text { mengetahui } \\
\text { informasi } \\
\text { jadwal } \\
\text { kuliah yang } \\
\text { ada pada } \\
\text { STMIK } \\
\text { Indonesia. }\end{array}$ & $\begin{array}{l}\text { Sistem ini } \\
\text { hanya } \\
\text { membahas } \\
\text { mengenai } \\
\text { informasi yang } \\
\text { akan } \\
\text { diberikan. }\end{array}$ \\
\hline
\end{tabular}

\begin{tabular}{|c|c|c|c|}
\hline $\begin{array}{l}\text { - Masih } \\
\text { terjadi } \\
\text { pemborosan } \\
\text { dalam } \\
\text { penggunaan } \\
\text { kertas dalam } \\
\text { penyampaian } \\
\text { informasi } \\
\text { jadwal mata } \\
\text { kuliah. }\end{array}$ & $\begin{array}{l}\text { Cause : } \\
\text { Hanya } \\
\text { ditampilkan } \\
\text { dalam bentuk } \\
\text { kertas yang } \\
\text { dipasang } \\
\text { melalui papan } \\
\text { pengumuman. } \\
\text { Effect : Akan } \\
\text { mengakibatka } \\
\text { n lambannya } \\
\text { proses } \\
\text { pengelolaan } \\
\text { data jadwal } \\
\text { kuliah. }\end{array}$ & $\begin{array}{l}\text { Dengan } \\
\text { adanya } \\
\text { sistem } \\
\text { online ini } \\
\text { dapat } \\
\text { bermanfaat } \\
\text { dalam } \\
\text { meminimalk } \\
\text { an biaya } \\
\text { yang } \\
\text { dikeluarkan. }\end{array}$ & $\begin{array}{l}\text { Proses sistem } \\
\text { tersebut } \\
\text { hanya } \\
\text { Pengelolaan } \\
\text { jadwal mata } \\
\text { kuliah, data } \\
\text { mata kuliah, } \\
\text { data dosen, } \\
\text { dan data } \\
\text { mahasiswa. }\end{array}$ \\
\hline
\end{tabular}

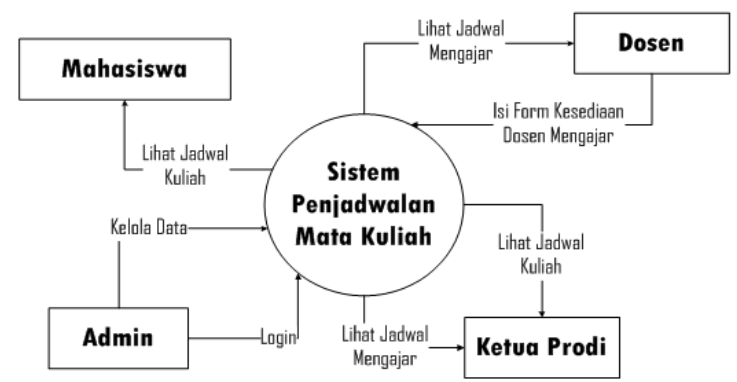

Gambar. Diagram Konteks Usulan

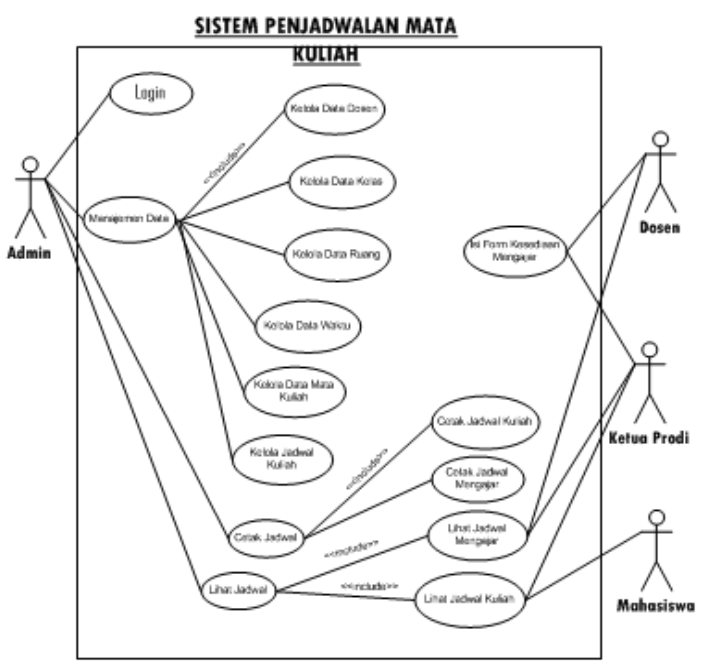

Gambar. Usecase Diagram

\section{Rancangan Permodelan Constraint \\ Programming}

Data-data yang harus dipenuhi dalam Constraint Programming untuk penjadwalan mata kuliah ini adalah sebagai berikut:

1. Tiap dosen mendapat tugas mengajar materimateri tertentu.

2. Tiap kelas digunakan untuk tingkat tertentu, dan diadakan pada shift tertentu. Ruang disini berarti "ruang kelas" secara fisik dan juga dimaknai sebagai "kelompok mahasiswa".

3. Tiap mata kuliah ditujukan untuk tingkat tertentu.

4. Tiap dosen memiliki kesanggupan mengajar tertentu, baik shift, hari, atau jamnya.

5. Tiap mata kuliah memiliki jumlah sks. 


\section{Dimensi dalam Permodelan Constraint Programming}

Dimensi adalah himpunan objek yang sama dan terlibat dalam penjadwalan kuliah. Dalam perhitungan, dimensi-dimensi ini menggunakan indeks angka integer untuk menggambarkan isi anggotanya. Jadi, dimensi ini dimodelkan sebagai array. Misalnya dimensi $D$ adalah himpunan semua huruf kapital, maka $D=\{A, B, C, D, . ., Z\}$. Dalam perhitungan Constraint Programming, maka $D$ akan menjadi array dan dinotasikan sebagai:

- $\mathrm{D}[0]=\mathrm{A}$

- $D[1]=B$

- $D[2]=C$

-

- $\quad \mathrm{D}[23]=\mathrm{Z}$

Dimensi-dimensi dasar dalam penjadwalan kuliah ini yaitu:

1. Shift (S), adalah shift-shift yang ada dalan jadwal kuliah, seperti:
a. Shift Pagi.
b. Shift Malam.
c. Dan seterusnya

2. Kelas $(\mathrm{K})$, adalah jumlah total kelas yang digunakan untuk proses belajar-mengajar, seperti:
a. Kelas 1.1
b. Kelas 2.1
c. Dan seterusnya

3. Jam (J), adalah jam-jam kuliah yang akan diadakan untuk tiap shift, seperti:
a. Jam $09.00-11.00$
b. Jam $11.00-13.00$
c. Dan seterusnya.

4. Dosen (D), adalah dosen-dosen yang akan mengajar mata kuliah tertentu, seperti:
a. Budi
b. Dede
c. Dan seterusnya.

5. Mata Kuliah (M), adalah mata kuliah yang akan diajarkan, seperti:
a. Statistik
b. Kalkulus
c. Dan seterusnya.

6. Tingkat $(T)$, adalah tingkatan-tingkatan yang ada pada kelas perkuliahan, seperti:
a. Tingkat 1
b. Tingkat 2
c. Dan seterusnya

7. Hari $(\mathrm{H})$, adalah hari-hari perkuliahan yang ada, seperti:
a. Hari Senin
b. Hari Selasa
c. Dan seterusnya

8. SKS (S), adalah jumlah sks yang harus dipenuhi setiap mata kuliah yang ada, seperti:

a. Statistik memiliki 2 sks.

b. Kalkulus memiliki 2 sks.

c. Dan seterusnya.

\section{Hubungan Antar Dimensi dalam Constraint Programming}

Dari masing-masing dimensi dasar di atas, ada hubungan-hubungan khusus dari beberapa dimensi yang berkaitan. Hubungan antar dimensi tersebut yaitu:
1. Dosen-Mata Kuliah (DM), adalah penugasan dosen untuk mengajar mata kuliah tertentu, misalnya:

a. Budi mengajar Kalkulus.

b. Dan seterusnya.

2. Kelas-Shift (KS), adalah penentuan kelas pada shift perkuliahan, misalnya:

a. Kelas 1.1 untuk Shift Pagi.

b. Dan seterusnya.

3. Kelas-Tingkat (KT), adalah penetapan kelas sesuai dengan tingkatnya, misalnya:

a. Kelas 1.1 adalah tingkat 1 .

b. Dan seterusnya.

4. Mata Kuliah-Tingkat (MT), adalah penetapan mata kuliah sesuai dengan tingkatnya, misalnya:

a. Statistik adalah mata kuliah untuk tingkat 1 .

b. Dan seterusnya.

5. Dosen-Shift-Hari-Jam (DSHJ), adalah data waktu mengajar dosen yang ditentukan jamnya setiap harinya, misalnya:

a. Budi mampu mengajar setiap hari dari jam 09.00 sampai jam 14.00

b. Dede hanya mampu mengajar hari Kamis saja, dari jam 13.00 sampai jam 15.00

c. Dan seterusnya.

\section{Langkah-langkah Algoritma Constraint \\ Programming}

Adapun langkah-langkah algoritma yang dilakukan dalam memasukkan data ke dalam sistem, yaitu:

1. Mendefinisikan data-data dimensi dasar, yaitu:
a. Shift (S)
b. Kelas (K)
c. $\operatorname{Jam}(\mathrm{J})$
d. Dosen (D)
e. Mata Kuliah (M)
f. Tingkat (T)
g. Hari $(\mathrm{H})$
h. SKS (S)

2. Mendefinisikan hubungan-hubungan antar dimensi yang ada, yaitu:
a. Dosen-Mata Kuliah (DM)
b. Kelas-Shift (KS)
c. Kelas-Tingkat (KT)
d. Mata Kuliah-Tingkat (MT)
e. Dosen-Shift-Hari-Jam (DSHJ).

3. Memasukkan variabel solusi ke dalam sistem.

4. Memasukkan semua batasan yang ada ke dalam sistem.

5. Memerintahkan sistem untuk menyeleksi domain-domain yang tidak perlu dimasukkan dalam perhitungan solusi.

6. Pencarian solusi, yaitu memerintahkan sistem untuk mencari solusi pertama yang didapat.

7. Pengambilan hasil solusi yang diperoleh dari sistem tersebut.

Tahap-tahap penjadwalan mata kuliah :

1. Pemilihan tahun ajaran dan semester

2. Penentuan ruangan dan shift

3. Pemilihan soft constraint dan prioritasnya

4. Pemilihan mata kuliah yang tidak membutuhkan ruang kelas 
5. Pemilihan slot waktu dan ruang kosong yang tidak diisi kegiatan perkuliahan.

6. Pemilihan mata kuliah yang mempunyai jadwal khusus.

7. Pemilihan mata kuliah yang merupakan kelas virtual.

8. Pemilihan dosen yang memesan waktu beserta shift dan hari yang dipesan.

9. Penentuan prioritas dosen yang memesan waktu mengajar.

10. Pemilihan dosen yang tidak menginginkan waktu ajar yang berurutan.

11. Pemilihan waktu (shift dan hari) yang tidak boleh ditempati mata kuliah semester tertentu

12. Penempatan jadwal mata kuliah

13. Pemilihan mata kuliah yang tidak mengadakan ujian.

14. Penempatan jadwal ujian.

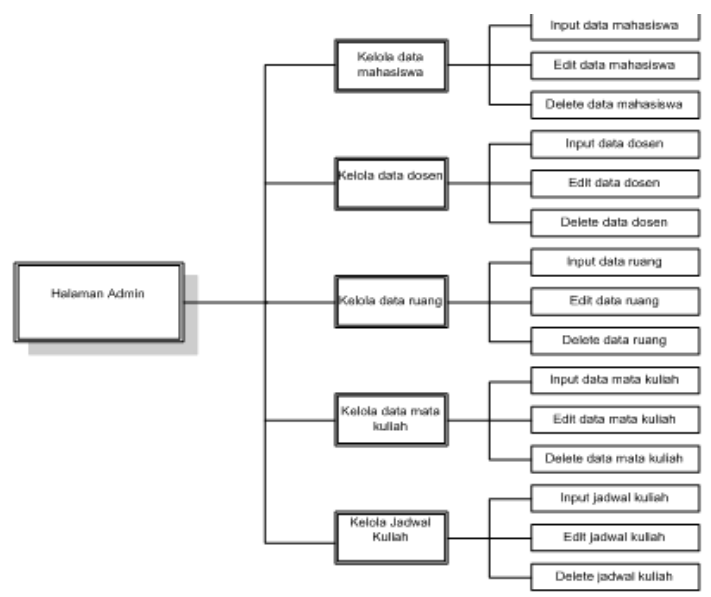

Gambar. Struktur Halaman Admin

\section{Menentukan Soft Constraint Beserta \\ Prioritasnya}

Tampilan menunjukkan bahwa item soft constraint yang dipilih akan ditambahkan pada list box. Sedangkan item yang tidak dipilih akan dihilangkan dari listbox. Setelah pilihan soft constraint muncul pada listbox, maka urutan prioritas batasan tersebut dapat diatur melalui tombol Up atau tombol Down. Item constraint yang dipilih akan naik 1 tingkatan dalam prioritas saat pengguna menekan tombol Up. Sebaliknya, jika pengguna menekan tombol Down, item constraint yang dipilih akan turun 1 tingkat prioritas.

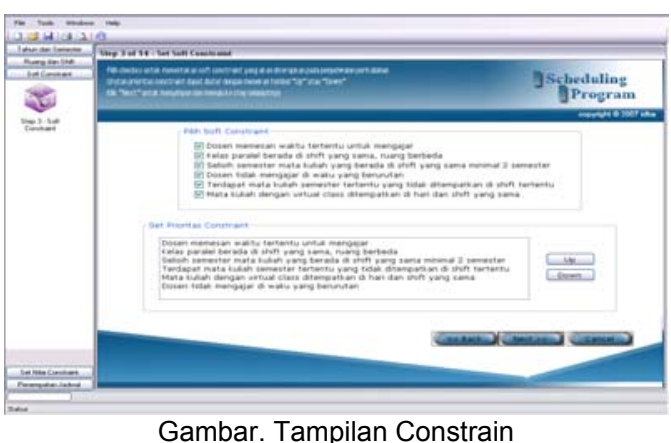

\section{Kesimpulan dan Saran}

Dengan menggunakan constrain programming maka

1. Membantu bagian administrasi Program Studi Sistem informasi dalam mengontrol data jadwal perkuliahan dalam penyajian informasi jadwal kuliah sehingga dapat dilakukan dengan cepat.

2. Memberikan informasi penjadwalan mata kuliah sesuai dengan kebutuhan.

\section{Saran}

Banyak sekali metode yang bias digunakan untuk membuat penjadwalan matakuliah, penulis menyarankan bagi yang ingin membuat tema yang sama bias menggunakan metode yang lain.

\section{DAFTAR PUSTAKA}

Nugroho, Eko. Sistem Informasi Manajemen Konsep, Aplikasi, dan Perkembangan. Yogyakarta: Andi. 2008.

Teguh Wahyono, 2004, Sistem Informasi : Konsep Dasar, Analisis Desain dan Implementasi, Graha IImu, Yogyakarta.

Wikipedia, 2014. Constraint Programming. (Online).

(http://en.wikipedia.org/wiki/Constraint progra mming, diakses 25 Juni 2014)

Lestarini, Dinda, $2010 . \quad$ Model-Model Pengembangan Sistem Informasi Berbasis Web, Fakultas IImu Kompute, Universitas Sriwijaya.

Arista, Gea, 2013. Logical Record Structure (LRS). (http://gea-gas.blogspot.com/2013/04/logicalrecord-structured-Irs.html, diakses 10 Juli 2014).

Yulia, Fajar, 2008. Penjadwalan Kereta Api Tunggal.

(http://digilib.itb.ac.id/files/disk1/625/jbptitbppgdl-fajaryulia-31250-2-2008ta-1.pdf.html, diakses 4 Juli 2014).

Anonymous, 2007. Landasan Teori Constraint Satisfication Problem. (http://thesis.binus.ac.id/Asli/Bab2/2007-200451-MTIF\%20Bab2.pdf, diakses 4 Juli 2014). 